\title{
The 5 Mortal Sins of New Product Development
}

\section{Kimberly Eddleston (Northeastern University)}

KEYWORDS: Entrepreneurship, Innovation, Marketing, Startups.

Sometimes an innovator or new company has an idea for a product that seems to have blockbuster potential -only to fizzle and flop. Why does this happen? In this interview with EIX's Kim Eddleston, Northeastern University Professor Stephen L. Golden discusses five mistakes that innovators and companies make that can doom a new product: not fixing a genuine need, solving a low-value problem, adding too many features, forgetting to validate the prototype with potential customers and "falling in love with the baby." 